\title{
Narratives on Ceramics
}

\author{
Yisha He \\ Central Academy of Fine Arts, Beijing, China \\ Email:469278215@qq.com
}

How to cite this paper: He, Y. S. (2021). Narratives on Ceramics. Art and Design Review, 9, 322-331.

https://doi.org/10.4236/adr.2021.94028

Received: October 8, 2021

Accepted: November 19, 2021

Published: November 22, 2021

Copyright (c) 2021 by author(s) and Scientific Research Publishing Inc. This work is licensed under the Creative Commons Attribution International License (CC BY 4.0).

http://creativecommons.org/licenses/by/4.0/

\begin{abstract}
I would argue that Richard Milette's object has been influenced by Greek elements to reconstruct its conception. He selected a classic Greek image as his vessel's decoration. As Liopold L. Foulem describes, "the Greek prototype chosen by Milette for this series is a true-to-life hydra, a generic, stereotypical form used because of its perverse association with art museums and, more accurately, with the study of Greek painting... by using faux Greek, pseudorestored pots and by substituting the painted narrative of the originals with a well-known contemporary easel painting". His ceramic vase's shape is the same with the ancient Greek vase, but it is built of many fragments, and it has obvious seam lines. Milette intends to highlight the damaged pieces, and his works are keenly collected. I believe his works are fine examples of postmodern ceramics (not sure if I got your meaning right here), because even though his image is a completely Greek scene, it cannot be described as a Greek narrative.
\end{abstract}

\section{Keywords}

Vase Painting, Transformation of Traditional Language, Comparison between China and the West, Ceramic Image Memorial

\section{Introduction}

When we want to commemorate a person, we can draw a picture, take a photo, and make a sculpture, but a more unique way is to make the person's image on a vessel.

My initial ideas about Greek pottery came from the examples of vases when I saw them in a Paris Museum for the first time. Every pot was described, showing scenes of local people's daily life or mythical tales. The images seemed mostly to be a tool for conveying emotion. Since prehistoric times, "visual culture" has been a part of people's daily life. Images were used not only to provide aesthetic feeling, but also to help our ancestors to understand the whole world more deeply. 
In my opinion, the ceramics narratives seem akin to the bible stories that have been decorated into churches by colorful stained-glass windows. Those images are like a kind of memory storage for human civilization. I'm fascinated by the tales depicted on the surface of many ceramics from that time. I consider that, for this reason, numerous artists have been inspired and utilized Greek cultural elements in their contemporary works. Furthermore, to focus on contemporary ceramics narratives, this would include artists such as Hilbert Boxem, Richard Milette, and Grayson Perry.

On the other hand, after the $20^{\text {th }}$ century, ceramics narratives underwent a dramatic change by artists. According to David Whiting, "a new sense in studio practice-that the message was as important as the medium-came from the fine arts, and a new interest in clay among painters and sculptors in late $19^{\text {th }}$ and early $20^{\text {th }}$ century" (Harvey, 1990). There is an extremely sensitive relationship between drawing and three-dimensional work. However, I would like to attempt to analyze various patterns and decorations of contemporary vessels; in modernism and postmodernism, it seems that many artists have used imagery to blur the vessels' contours.

Ceramic is a very traditional artistic language. Comparing ancient and modern or Chinese and Western ceramic vase stories is a process to explore the transformation from a traditional language to a contemporary language.

\section{Narratives on Historical Ceramics}

\subsection{Greek Vases}

\subsubsection{Narratives on Original Greek Vessels}

In my opinion, many of the most interesting parts of human culture originate from ancient Greece. It seems that if you hunger for knowledge of Western culture, then going to read Bible and Greek tales is a great way to learn its core.

The painting of Greek pottery can be divided into different periods, each with their own typical characters. Black- and red-figure is only one type of Greek pottery painting, but also the most plentiful style among all ancient Greek vessels. It includes numerous narratives about Greece. "If one is looking to the beginnings of any major ceramics narratives tradition in Europe, it is most likely the blackand red-figure painted vases of Classical Greece that first spring to mind" (Ostermann, 2006). The drawings' details are pretty clear and the contour lines are smooth and elegant. The painting's detail has extremely high quality, and looks like a professional painter, rather than a normal folk crafter, made it. Based on this, I thus agree with the view of Matthias, that "Many historians consider the Greek vase painters to be true painters, rather than mere vessel decorators" (Ostermann, 2006). In addition, we can see the signatures of painters on the vessels' bottoms. Maybe for this reason, I consider that painting would be the "major" art during that time. I am not sure if I could judge the social status of those painters, but we are able to find from certain documents out that painting seems the most important technique of the whole process for pottery making. "The Greeks 
had already learnt the use of other colours than the white and red found on vases; Polygnotus certainly employed blue, yellow and green. But drawing remained the main skill involved; Greek paintings were only coloured drawing until the time of Zeuxis" (Mingazzini, 1969).

"Like most cultures, the Greeks used myths as parables for contemporary events. Frequently retold pictorial narratives (such as the heroic deeds of Heracles and Theseus) reinforced the ancient Greeks' world vision and mainstream political thought," says Matthias (Ostermann, 2006). My focus here is not about those two heroes, yet I am interested in whether the narratives described real historical issues or were merely imaginations from our ancestors. My question is whether those paintings were made in order to record or glorify heroic events. Some of the imageries clearly show scenes of people's daily life. "The narrative imagery painted on these vessels provides one of the major sources of insight into ancient Greek daily life, attitudes and beliefs" as Matthias writes (Ostermann, 2006).

However, many myths have appeared on potteries as well. For instance, we are able to see the emergence of a number of topics about Apollo, and these themes include Dai Di Adams and Bailey's wedding (Le marriage de Thetis et Pelee). We also often talk about the Heracles tripod fight (Heracles dispute avec Apollon pour le trepied), or brother and sister of Apollo (Les jumeaux sauvent leur mere Leto) and so on. If today we talk about Apollo, who is always shown as a young Titan, there will be several images in our minds that immediately surface: $\mathrm{He}$ is a tall and very noble, has a handsome face, does not wear clothes, is often sitting on a majestic carriage associated with the sun, and so on.

To focus on those imageries, it is important to remember that there are several characteristics: First, it is rare that Apollo appears alone, since he is one part of a key twin siblings' relationship in Greek myth. Secondly, Apollo is rarely a "background character" on any vase but is usually the focus of the story. Finally, Apollo will be more able to accept our modern image of nudity, is powerful and so that will have to wait until about five centuries red de arise gradually as the line shape, which should have a contemporary aesthetic inseparable.

In pottery, the records drawn from the Greek narratives are of great importance. Numerous historical records and academic research have joined the author's subjective conjecture. Thus, if the vessels' description in the story is true, it is difficult to draw a conclusion.

\subsubsection{Greek Elements on Other Ceramists' Works}

Whatever the answer to the above question is, Greek traditional art has been applied by many modern artists through their own works. For various reasons, Greek elements always inspire the enthusiasm of contemporary artists. "Dutch sculptor Hilbert Boxem has recently completed a series of works which abstract high points in ceramic history-Greek attic vase painting, Hispano Moresque luster decoration, the graphic beauty of Chinese and Delft blue and white. He then creates a surreal twisted form in which fragments of the particular style, in this case the 
classical Greek vase, are distorted and converted from vessel to pure sculpture," Mark Del Vecchio says.

As David Harvey mentions, "here is Gertrude Stein writing on Picasso in 1983: As everything destroys itself in the twentieth century and nothing continues, so then the twentieth century has a splendor which is its own and Picasso is of this century, he has that strange quality of an earth that one has never seen and of things destroyed as they have never been destroyed. So then Picasso has his splendor" (Harvey, 1990). Today, people generally are more interested in Picasso's sketches or oil paintings; yet, for me, his ceramics work is another great highlight. After my trip to several Greek museums, I consider that Picasso's ceramics have mostly been influenced by Mid-sea Mediterranean culture, particularly the Greek vase.

Comparing both, I found out some quite similar points. For example, Picasso drew the vessel's surface as an animal, and then decorated the pot's rim, neck, body and feet by painting to make it look like an intact animal; in the National Archaeological Museum of Greece, I saw a figure that was extremely similar with Picasso's ceramics work.

I would argue that Richard Milette's object has been affected by Greek elements to reconstruct its conception. He selected a classic Greek image as his vessel's decoration. As Liopold L. Foulem's describes, "the Greek prototype chosen by Milette for this series is a true-to-life hydra, a generic, stereotypical form used because of its perverse association with art museums and, more accurately, with the study of Greek painting... by using faux Greek, pseudo-restored pots and by substituting the painted narrative of the originals with a well-known contemporary easel painting" (Vecchio, 2001). His ceramics vase's shape is same as the ancient Greek vase, but it is built of many fragments, and it has obvious seam lines. Milette intends to highlight the damaged pieces, and his works are keenly collected.

I had tried a similar method for my previous work; firstly, I made the shape of Greek vessels, then I cut them by different approaches, and finally joined the fragments together and painted the damaged parts, giving the work a fresh life. It looks intact in form, but it obviously has been damaged. My essential meaning is that the piece should help people to recall how much ancient culture has been ruined during the progress of history.

However, modern people have realized that civilization should be protected, and work to restore it in many ways, and I wanted my vase to show this too. Furthermore, I attempted to combine Greek figures and my unique patterns by drawing. The Greek figure seems a significant mark for my "Postmodernist" work.

One of her works gave me quite a deep impression, namely her piece "The Greek boy goes to Tokyo". Three-coloured vases have a "Greek handle" without any pattern decoration. It is as if these Greek jars wear Japanese fashion dress, making them bright and lively. 


\subsection{Chinese Ceramics Narratives on Blue and White}

\subsubsection{Stories on Ancient Chinese Ceramics}

When Chinese porcelain was introduced into Europe in the $14^{\text {th }}$ century, Chinese porcelain was regarded as an extremely rare treasure. It is a matter of commemorative value for European nobles to record important people's stories on ceramic vessels. If this tradition can continue to today, how will it change the composition of the picture?

"It was, write Bradbury and McFarlane... One can draw maps showing artistic centres and provinces, the international balance of cultural power - never quite the same as, though doubtlessly intricately related to, the balance of political and economic power. This quote doesn't make sense. The maps change as the aesthetics change..." David says in his article (Harvey, 1990). Based on this point of view, China has same situation in the ceramics area. From the Yuan Dynasty until the Qing dynasty, Jingdezhen city was the central ceramic place for China's creation and export of porcelain. This city has been regarded this way for around a thousand years because of its "kaolin" clay and "blue and white" decoration.

Focusing on Chinese ceramics of the Ming dynasty and Qing dynasty, blue and white attained its crowning achievement. It is not only about quality of material, but also its pattern, which underwent dramatic development. The ceramics' surface began to show more special stories, rather than leaves or flower patterns, as in the Yuan or earlier Ming dynasty. "The first real venture into narratives, specifically on vessels, did not really occur until the early 1600s, during the final decades of the Ming dynasty (AD 1644-1911)." Matthias says (Ostermann, 2006). Some extremely popular tales occurred in Chinese folk opera as well as on vessels repeatedly. For example, "The Romance of the Western Chamber" and "The Peony Pavilion" both occurred on vessels numerous times.

"The drama Xixiang Ji, generally known in English as the Romance of the Western Chamber was perhaps one of the best known and most popular dramas of pre-modern China. Its origins go back to a Tang dynasty prose tale, Yingying Zhuan (or the biography of Yingying) by Yuan Zhen (AD 779-831)... In the form of this drama the story has maintained its popularity to the present day" Says Matthias (Ostermann, 2006). We are still able to see many daily ceramics painted with scenes of those tales, and particularly in works from the ceramics factories of Jingdezhen. The stories of Romance of the Western Chamber and The Peony Pavilion are both too long to explain here, but to quote Matthias' description, "the talented but impoverished scholar Zhang Sheng, while staying in a monastery, met the beautiful girl Cui Yingying, accompanied by her maid and formidable mother Madam Zheng. Aided by the clever and scheming maid Hongniang, the lovers gradually form a clandestine liaison, which of course is strenuously opposed by mother Zheng as unsuitable. Our scholar is sent away to pass his imperial civil service examinations, and in this he succeeds, finally returning in inevitable triumph to claim his bride" (Ostermann, 2006). All parts of the whole story have occurred on vessels frequently. 
However, compared to the late Ming and early Qing porcelain and its overwhelming use of "The Romance of the West Chamber," scenes from the "The Peony Pavilion" are far less common. In this story, the female protagonist, Du Liniang, is much less fortunate than Cui Yingyiing, for her dream-lover died. The original script was written by Tang Xianzu, a playwright in Ming dynasty, and today has become a symbol of innocence.

It is worth noting that the Western religious community is similar totraditional Chinese society, in that women have been excluded from the family line, and marriage is often for the purpose of the exploration of sex. Therefore, the image of Liniang on the vessel could show that she is an autonomous woman, facing the audience rather than an image with "decency and propriety" that men or the patriarchal society demand.

As Yibin explains, "porcelain painters in no uncertain terms, with nearly half of girls Huaichun the publicity impact of rationality of the existence of desires, and increase the proportion of the main characters of this breakthrough design is extremely effective in enhancing the impact of the screen will be simple 'narrative paintings' I don't understand this at all. Translate it again, yourself, don't use an online service! The story has developed into an incentive to promote the liberation of women through visual stimuli" (Ni, 2008).

Furthermore, I suggest, generally speaking, we are able to recognize who is the leading role of the story from the image, since the servant girl's figure would be obviously smaller than the leading character, and there are also different dress styles.

"In traditional Chinese figure painting, the servant girl's figure is always shorter than the master, and clothing is also simpler, such as a low bun, with fewer hairpins and plainer dress" (Ni, 2008). In addition, men always towards female figures in those images, yet peeping men, the look steadily forward. Ideological orthodoxy has been the spread of powerful support, however, almost every era of the vulnerable groups in society also has their own acts of preferences, but the mainstream has been excluded, repressed, and not readily available and popular exposure.

\subsubsection{Blue and White by Modern Ceramists}

To look back to European tin-glaze traditions, I feel that painters use blue and white as if it were a water-colour to decorate ceramics, especially for tiles.

Del Vecchio writes that, "there is Milette who invokes blue and white as 'cultural treasure' in his mantelpiece garniture set of vases. The handles are grand and gilded, but the vessels are made up of blue-and-white shards and suggest an archaeological, museum context". Milette used a similar method to make a series of vessels in blue and white, naming it "Garniture with blue and white".

Charles Krafft is another American artist who has applied blue and white in his commercial work. "His blue-and-white works began in earnest with his 'Disaster wares' which satirized the common souvenir plate. They 'celebrated' tragic events such as the sinking of the Titanic with tongue-in-cheek adherence to po- 
pulist style", Del Vecchio writes (Vecchio, 2001).

I used to paint the patterns' contour in blue and white by brush. Blue and white is a kind of stain, and Del Vecchio once explained blue and white by noting that "Blue and white is the most popular form of decoration in the entire history of ceramics, and the eighteenth-century blue willow pattern which draws from this tradition is the most successful single pattern ever devised for ceramic ware, still in production in massive quantities today... No other style of decoration is more ubiquitous or more relentlessly popular" (Vecchio, 2001). Obviously, blue and white has attracted many artists to apply it into their works-Charles Krafft, Robert Dawson, Richard Milette and Paul Scott for example. These artists have pushed this material into another stage of artistic expression.

"Blue and white was the most favoured colour combination for transfer printing and ultimately alludes to its source of inspiration in Oriental blue and white, but the imagery is based entirely on a European world view. Blue and white plates were the perfect adornment for display furniture such as the dresser, which became a central feature in many nineteenth-century homes", Vincentell says.

I use drawing to describe the narrative with loose lines, and those lines are created according to the wares' shape. They combine both Western and Eastern cultural elements, and also some of my personal emotions. In addition, I like to try to apply images on my ceramic pieces with print technique. "Printing on pottery is a liberating force in contemporary studio ceramics," says David (Harvey, 1990).

Joan Miro's work is a major influence on me, and I especially admire his oil paintings that are full of childlike innocence and poetry. As Breton says, Miro is the most authentic super-realist. He experienced animals, Cubism, and Dadaism before he became a Realist; as a super-realist, he started painting in a child-like manner, creating paintings that are spontaneous in nature, with a kind of childlike happiness. This reflects the artist's skilled grasp of shape and color. Also, David Whiting mentions that, "far more than token, Miro's ceramic projects were those of a true artist-potter, whose preternatural iconography seemed to grow organically out of the material" (Greenberg, 1948).

I was also interested in Greek vases for their regular shape. Like Miro, I tried to explore shape and color, but using ceramics rather than canvas. I made a mould of similar form to Greek style, and then cut down the model into a half, a quarter, and eight equal pieces. It looks like another rethinking of creating the ancient shape. It does offer cultural elements, yet it has purely absorbed the original Greek form.

\section{Contemporary Ceramics Narratives}

Canadian artist Matthias Ostermann used the Bible story of Adam and Eve as his plate's image. His loose drawing lines deconstruct the classical scene with a modern perspective. The apple tree and the snake (symbolic of aspiration) demonstrate a kind of rethinking for traditional religion culture by artists. “...recounts 
the familiar story of 'Adam and Eve', although in perhaps a terser form than the innocent English delftware image portrayed in... Nonetheless, I do believe that this ancient narrative can still be read as contemporary for our own time", Matthias writes (Ostermann, 2006).

With the development of the Industrial Revolution, print became another important method that is still applied by contemporary ceramists. "Industry has exploited print processes and within the reach of most people" (Scott \& Bennett, 1996). This technology seems a kind of replacement of the painting brush. There is not only decoration by drawing brush, but also patterns made by decal. This began to increase the speed of production and injected the blood of "modernism" or "postmodernism" into clay.

Grayson Perry's work is a typical example for applying print. His works combine both purely drawing lines and print parts. I enjoy his composition of the whole vessel's surface. "Grayson Perry epitomizes this confrontational approach, using an apparently promiscuous array of printed decoration, which is actually selected for precise meaning rather than arbitrary offensiveness" (Motherwell, 1951).

Perry is the Postmodernist ceramist whom I admire the most. He describes his stories on pots by overlapping drawing, creating images that are fascinating. "The forms are a little lumpen, the handling of the clay suggests folk craft, rather than a sophisticated artist who actually lives and works in London, until one begins to put together all the elements-drawings, relief modeling, decals, lusters, and increasingly beautiful glazes... The drawings that cover the surface are often obscene and provocative. To this is added a plethora of related decal images, mostly overly decorative and of a regressive taste" (Vecchio, 2001). Focusing on his images' context, they clearly describe some true stories.

They do include significant historical issues, but also some daily events. "He uses his own complexity and contradictions (cross-dresser, hard-core biker, athlete, father, husband) to refract messages off the many, mirrored splinters of his life so that these truths are shown" (Pagliaro, 2003). Perry attempted to play a housewife's role and incorporate such feeling into his work, the dialogue between the pot and himself being a kind of reflection of a paradoxical society.

As David writes, "modern environments and experiences cut across all boundaries of geography and ethnicity, of class and nationality, of religion and ideology; in this sense, modernity can be said to unite all mankind. But it is a paradoxical unity, a unity of disunity; it pours us all into a maelstrom of perpetual disintegration and renewal, of struggle and contradiction, of ambiguity and anguish" (Harvey, 1990). Therefore, when Perry explains his unique emotion through these real narratives, they seem closely related to struggle and suffering.

Recently, a "vessel as image" approach has been applied in tableware works by some contemporary ceramists. As Del Vecchio says, "there is a difference between work that contains a chance element of postmodern vocabulary, such as decoration, for instance, and work that deliberately uses decoration, as in the work of 
Betty Woodman. Before she became part of the Pattern and Decoration movement ( $\mathrm{P}$ and $\mathrm{D})$ her decorated pottery was lively and vital, but not postmodern." However, in the late 1970s, after she became involved in P and D, her work changed dramatically in its scale, its ambition, and its context, and became Postmodern (Vecchio, 2001).

At the end of $19^{\text {th }}$ century, Symbolist painting had been deeply influenced by the aesthetic movement of British literature. Accordingly, I will try to relate this concept with contemporary ceramics.

"After all the very word 'print' means to impress, and what more impressionable material is there than clay?” writes Paul Scott (Scott \& Bennett, 1996). Print is one of the extremely important methods for making ceramic images, and this is something I look forward to applying in my future works. In some ways I feel that using ancient techniques such as printing gives me a closer link to historic ceramics; yet it also gives me the opportunity to update those ceramics with a modern and even postmodern perspective.

Some artists have tried to use this technique to make decal and overlapping patterns. Particularly, when I look at Perry's work, his images have several layers. It recalls Harvey's words, “resorting to the techniques of montage/collage provided one means of addressing this problem, since different effects out of different times (old newspapers) and spaces (the use of common objects) could be superimposed to create a simultaneous effect" (Harvey, 1990).

Perfect form needs very little surface embellishment. Greg Payce's narrative made into his work's shape; he does not apply imagery instead to create unique contour. As Matthias writes, "Greg Payce explores the 'human figure' spaces between carefully placed albarello-like shapes and confronts the viewer with a new visual premise" (Ostermann, 2006). His work supplies me with fresh inspiration to make a new mould, which means my form is able to combine both two- and three-dimensional narratives.

However, I would like to decorate the surface with drawing line and print. I feel this could be a kind of rethinking of modernism and postmodernism by my studio practice. Furthermore, I consider that it could become an integration of Western and Eastern elements.

\section{Conclusion}

The question is, as David suggested, “did Ming vases, Grecian urns, and Dresden China all express some common sentiment of beauty? But it also arose out of the sheer difficulty of translating Enlightenment principles of rational and scientific understanding into moral and political principles appropriate for action" (Harvey, 1990).

In my opinion, war brings communication as well as miseries for our society. Many fresh and great arts or "isms" have grown out of war and trade. This "arose in part out of the need to come to terms with the immense variety of cultural artifacts, produced under very different social conditions, which increasing trade 
and cultural contract revealed", David Harvey writes. Fortunately, later people could read their predecessors' mental world via those ceramic imageries; meanwhile, artists are able to recreate the narratives by their own strategies for making ceramic pieces. Looking at the procession from modernism to postmodernism, we cannot recount how many artists spent how much time and effort on it.

Time keeps moving forward, which is why contemporary ceramics narratives will continue to be developed by creative artists. As Harvey says, "if modern life is indeed so suffused with the sense of the fleeting, the ephemeral, the fragmentary, and the contingent, then a number of profound consequences follow" (Harvey, 1990: p. 11). People have always doubted how to make a boundary between modernism and postmodernism, and some even attempted to totally change or overthrow the former and explore its clear and definite characters. "Postmodernist characters often seem confused as to which world they are in, and how they should act with respect to it", Harvey writes (Harvey, 1990).

The modernity of ceramics is also in the creation and thinking of many contemporary artists. They have completely separated the past practicability to capture its metaphysical value. The irreplaceability of ceramics lies in its fragile, unpredictable, strong plasticity and other sensitive properties. The story depicted on ceramics also has unique social value with the thinking and exploration of contemporary artists.

\section{Conflicts of Interest}

The author declares no conflicts of interest regarding the publication of this paper.

\section{References}

Greenberg, C. (1948). The Crisis of the Easel Picture. Arno Press.

Harvey, D. (1990). The Condition of Postmodernity. Blackwell.

Mingazzini, P. (1969). Greek Pottery Painting. Paul Hamlyn.

Motherwell, R. (1951). The Dada Painters ad Poets. Schultz, Inc.

Ni, Y. (2008). Kan Tu Shuo Ci. Zhonghua Book Company.

Ostermann, M. (2006). The Ceramic Narrative. University of Pennsylvania Press.

Pagliaro, J. (2003). Shards. Garth Clark on Ceramic Art.

Scott, P., \& Bennett, T. (1996). Hot off the Press: Ceramics and Print. Bellew Publishing.

Vecchio, M. (2001). Postmodern Ceramics. Thames \& Hudson. 